\title{
Broken rotor bar fault detection in line start permanent magnet synchronous motor using transient current signal
}

\begin{abstract}
One of the high efficiency motors that were introduced to the industry in recent times is Line Start Permanent Magnet Synchronous Motor (LS-PMSM). Fault detection of LS-PMSM is one of interesting issues. This article presents a new technique for broken rotor bar detection based on the values of Mean and RMS features obtained from captured start-up current in the time domain. The extracted features were analyzed using analysis of variance method to predict the motor condition. Starting load condition and its interaction on detection of broken rotor bar were also investigated. The statistical evaluation of means for each feature at different conditions was performed using Tukey's method as post-hoc procedure. The result showed that the applied features could able to detect the broken rotor bar fault in LS-PMSMs.
\end{abstract}

Keyword: ANOVA; Broken rotor bar; Current signal; LS-PMSM; Transient 